\title{
SCIENTIFIC PAPERS
}

\section{Predictors of disability in a longitudinal sample of patients with rheumatoid arthritis}

\author{
J Paul Leigh, James F Fries
}

\begin{abstract}
Information from the Health Assessment Questionnaire (HAQ) is used to identify which variables measured in 1981 successfully predict the severity of disease in $\mathbf{1 9 8 9}$ and the eight year change in severity of disease in a sample of 330 residents of Santa Clara County, California, USA. This study is exploratory and no previous hypotheses are made. Using univariate correlations and stepwise linear regressions, initial values of a number of variables are found to be useful predictors including, in order: the HAQ disability index, pain scale, global health status, tender joints, few work hours, age, female sex, never married, widowhood, and occupation as operative (e.g. dry wall installers, assemblers). Data suggest that deterioration over eight years is least rapid for those with severe disease in 1981. A mathematical identity suggests that analyses of the changes in severity versus analyses of 1989 severity are identical, provided that the 1981 disability index is entered as a covariate. The initial level of the disability index of the HAQ is by far the strongest predictive variable and provides a clinically important gauge for the likelihood of future impairment.
\end{abstract}

Rheumatoid arthritis is a progressively debilitating disease, but not everyone progresses at the same rate. Some evidence suggests that the disease progresses more quickly in women compared with men, and in those over the age of 60 years compared with those less than $60 .{ }^{1}$ Only a few studies have attempted to identify risk factors or even verify the age and gender findings which might indicate which patients with rheumatoid arthritis are more likely to quickly progress to disability or death. The few published studies use small sample sizes, short follow up periods, poor baseline data, and often do not rely on now widely accepted questionnaire methods to measure the disease. ${ }^{2-7}$

In this study one of the most commonly used instruments is used to measure outcome in rheumatoid arthritis: the Health Assessment Questionnaire (HAQ). The sample consists of 330 patients living in Santa Clara County, California who have been followed since 1981 . The sample comprises a closed cohort of patients with rheumatoid arthritis. The HAQ data are used on these 330 patients to assess those variables measured in 1981 which predict the severity of rheumatoid arthritis in 1989 and the change in severity over eight years.

\section{Patients and methods}

PATIENTS

In 1978 the Stanford Arthritis Center began placing newspaper advertisements and notices in Chemists throughout Santa Clara County. The notices asked for volunteers to participate in a longitudinal rheumatoid arthritis study. The goal was to establish a community cohort which, although self selected, was nevertheless not subject to the usual bias of selection by specific attendance at a clinic. By 1981 over 500 subjects had filled out detailed questionnaires and had expressed interest in continued participation. Of these, 330 were judged to have definite or classical rheumatoid arthritis with five or more criteria and with a diagnosis by a doctor. The questionnaires completed were the HAQs. We take 1981 as our starting date as it was in this year that all previous information on the 330 subjects was entered into ARAMIS computers as one closed cohort. Deaths, general attrition, and missing values on key variables reduced the sample size to 209 by the first half of 1989, the final year used for this study. The age and gender characteristics of our sample are typical for studies on rheumatoid arthritis. ${ }^{17-9}$ The average age of all subjects was 54 years at the beginning of the study, and $82 \%$ of all subjects were women. The average education level, almost 14 years, was slightly higher than the average for the USA, but is typical for Santa Clara County. ${ }^{1011}$

\section{MEASUREMENTS}

The disability index in this $\mathrm{HAQ}$ and the sum of the disability index, global health status, and pain scale measured in 1989 served as the dependent variables for this study. This HAQ, a multidimensional instrument developed by the Stanford Arthritis Center, measures outcome in terms of mortality, disability, pain, iatrogenic events, and economic impact. ${ }^{8} 91213$ Disability index is measured in eight categories: dressing and grooming, rising, eating, walking, hygiene, reach, grip strength, and outside activities. The reliability and validity of the HAQ have been previously reported. ${ }^{12}{ }^{13}$ The disability index is continuous and ranges between and includes 0 and 3. An additional dependent variable, SUM, was also analysed. SUM represented the sum of three HAQ measures: the disability index, the pain scale, and a global health status scale. Each of these three was coded to have a minimum value of 0 and a maximum of 3 . The pain scale is measured by the respondent's mark on a horizontal analogue scale. A mark far to the left indicates the 
respondent has no pain. A mark far to the right indicates the respondent has severe pain. Global health status is measured similarly; the respondent must make a mark along a horizontal line. The global health status ranges between and includes 0 and 100 , but was recorded to lie between and include 0 and 3 .

\section{ANALYSIS}

Nearly 400 entry variables, assessed by prospective protocol, were available for these patients. Most variables were eliminated from formal testing for predictive power on clinical grounds or because of the low occurrence of events. Variables eliminated at this level included vasculitis, neuropathy, eosinophilia, dyspnoea, and specific patterns of joint disease. The 56 remaining variables were formally tested using univariate correlations and forward stepwise multiple linear regressions. Candidate predictive variables were required to generate a $p \leqslant 0 \cdot 15$ value to be selected by the stepwise routine. The dependent variables were the disability index and SUM, measured in 1989 and the 1989 minus the 1981 disability index. For stepwise regression, the candidate variable most strongly correlated with subsequent disability or SUM was selected first, then the variable providing the most additional information when combined with the first, and so on. An advantage of such linear regression analysis is its ability to accommodate a continuous rather than a dichotomised dependent variable, thus increasing statistical power.

In the regression process, an information coefficient or $R^{2}$ value summarises the predictive information available after each step of the regression. This information increases monotonically in successively smaller increments until it levels off at an asymptote of less than unity. The level of the asymptote is a measure of the maximum predictive information of our covariates and is an index of the relative difficulty of the problem. $\mathbf{R}^{2}$ is the percentage of the variation in the dependent variable that can be 'explained' by variations in the independent variables of the regression.

\section{Results}

Table 1 presents characteristics of the sample. Although the sample size began with 330 in 1981, by 1989121 people had either died, could not be followed, or refused to participate. There

Table 1 Characteristics of the sample* from Santa Clara County, California

\begin{tabular}{|c|c|c|c|}
\hline & $\begin{array}{l}\text { Alive and in } \\
\text { sample 1981-9 } \\
(n=209)\end{array}$ & $\begin{array}{l}\text { Died sometime } \\
\text { during 1981-9 } \\
(n=54)\end{array}$ & $\begin{array}{l}\text { Lost to } \\
\text { follow up } \\
(n=67)\end{array}$ \\
\hline $\begin{array}{l}\text { Mean (SD) age in } 1981 \text { (years) } \\
\text { Percentage female in } 1981 \\
\text { Percentage white in } 1981 \\
\text { Mean (SD) duration of illness in } \\
1981 \text { (years) } \\
\text { Mean (SD) duration of illness in } 1989, \\
\text { alive (years) } \\
\text { Mean (SD) disability index in } 1981 \\
\text { Mean (SD) disability index in } 1989 \text {, alive } \\
\text { Mean (SD) years of education in } 1981 \\
\text { Percentage of subjects married, spouse } \\
\text { present in } 1981\end{array}$ & $\begin{array}{l}52(14) \\
86 \\
82 \\
12(9) \\
19(8) \\
1 \cdot 09(0 \cdot 83) \\
1 \cdot 16(0 \cdot 81) \\
14 \cdot 2(2 \cdot 4) \\
65 \cdot 7\end{array}$ & $\begin{array}{l}66(10) \\
63 \\
93 \\
18(9) \\
\overline{1} \cdot 75(0 \cdot 88) \\
\overline{13} \cdot 4(2 \cdot 5)\end{array}$ & $\begin{array}{l}55(12) \\
85 \\
84 \\
14(9) \\
\overline{1 \cdot 20}(0 \cdot 09) \\
\overline{13} \cdot 7(2 \cdot 8)\end{array}$ \\
\hline
\end{tabular}

were a few statistically significant differences across the first two groups identified in table 1. Statistical significance was assessed by constructing $t$ tests for the difference in means and dividing by standard errors. Statistically significant results are the following: subjects alive and in the 1981 and 1989 sample (column 1) were younger than the deceased (column 2), more likely to be women, less likely to be white, had a shorter duration of disease and lower initial disability than the deceased subjects. There were no statistically significant differences between those alive and continuously in the sample in column 1 versus those lost to follow up in column 3.

Table 2 presents the results of univariate correlations in the 209 continuously enrolled subjects surviving until 1989 . The dependent variable was the disability index in the first six

Table 2 Univariate predictors of subsequent disability Univariate correlation coefficients with the disability index measured in 1989 and independent variables measured in 1981

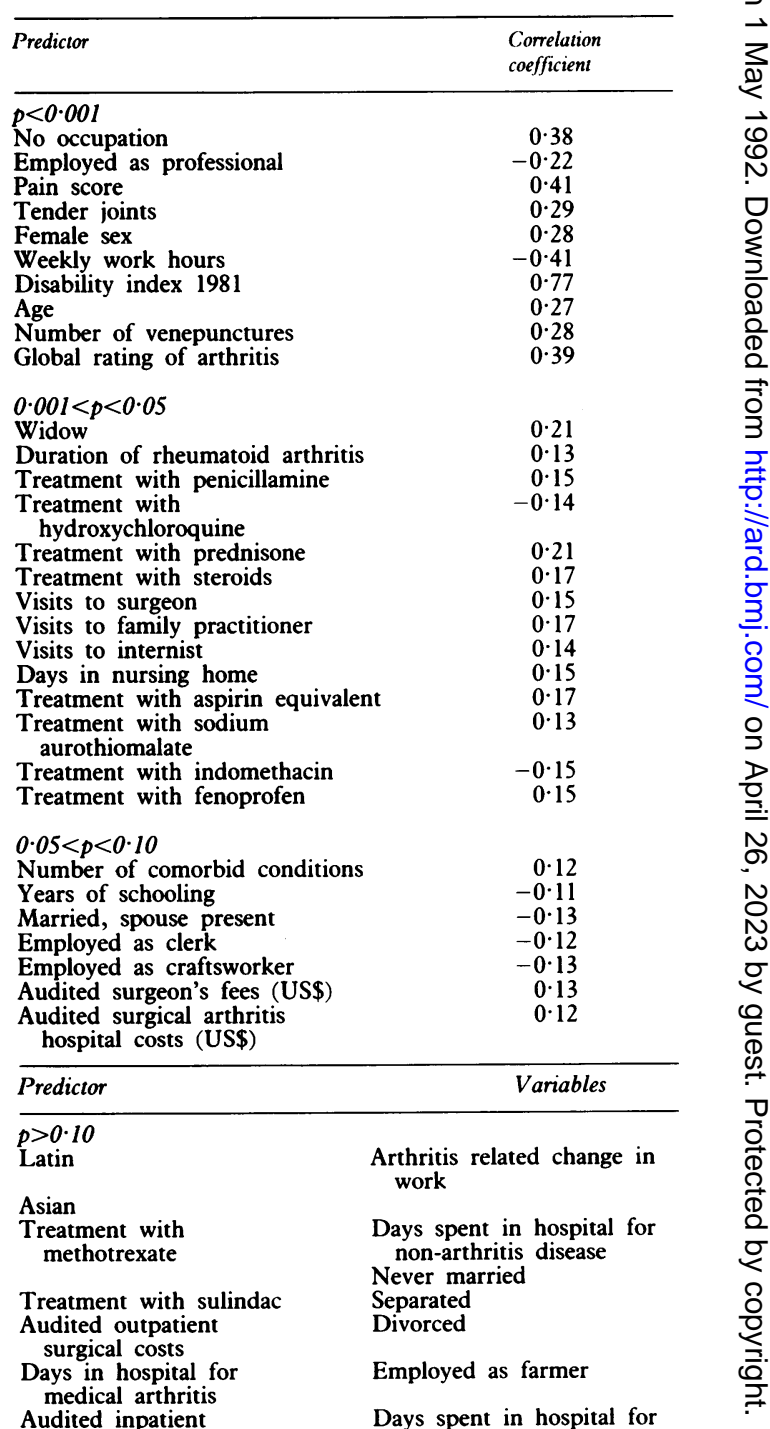

Audited inpatient medical doctor Audited medical arthritis hospital costs Treatment with tolmetin Treatment with naproxen Black White 
months of 1989 and the independent variables were measured in the last six months of 1981 . Of the four variables with the largest correlation coefficients, three were unique to the HAQ: the disability index, the pain scale, and the global health status score, all measured in 1981. Note

Table 3 Predictors of subsequent disability. Forward stepwise regression: 1989 disability index for living respondents is the dependent variable

\begin{tabular}{llcl}
\hline $\begin{array}{l}\text { Independent variables } \\
\text { measured in 1981 }\end{array}$ & $\begin{array}{l}\text { Step } \\
\text { entered }\end{array}$ & $\begin{array}{l}\text { Coefficient } \\
\text { estimate }\end{array}$ & $\begin{array}{l}\text { Estimated } \\
\text { standard error }\end{array}$ \\
\hline Disability index, 1981 & 1 & 0.840 & 0.059 \\
Work hours & 2 & -0.006 & 0.002 \\
Employed as farmer & 3 & 1.033 & 0.348 \\
Global health status, analogue scale & 4 & -0.003 & 0.002 \\
Employed as sales person & 5 & 0.314 & 0.148 \\
Widow or widower & 6 & 0.263 & 0.120 \\
Number of visits to a general practitioner & 7 & 0.057 & 0.025 \\
Treatment with indomethacin & 8 & -0.002 & 0.001 \\
Education level & 9 & 0.021 & 0.014 \\
\hline
\end{tabular}

Sample size $=209 ; R^{2}$ in final regression $=0.659$.

Table 4 Predictors of subsequent health status forward stepwise regression: SUM of the 1989 disability index, the global health status scale, and the pain scale is the dependint variable. Deceased patients included and given maximum value for the SUM of 9

\begin{tabular}{llcl}
\hline $\begin{array}{l}\text { Independent variables } \\
\text { measured in 1981 }\end{array}$ & $\begin{array}{l}\text { Step } \\
\text { entered }\end{array}$ & $\begin{array}{l}\text { Coefficient } \\
\text { estimate }\end{array}$ & $\begin{array}{l}\text { Estimated } \\
\text { standard } \text { error }\end{array}$ \\
\hline Disability index & 1 & 1.52 & 0.20 \\
Age & 2 & 0.06 & 0.01 \\
Treatment with prednisone & 3 & 0.06 & 0.03 \\
Work hours & 4 & -0.02 & 0.01 \\
Female sex & 5 & 0.90 & 0.38 \\
Never married & 6 & 1.05 & 0.46 \\
Employed as farmer & 7 & 3.46 & 1.61 \\
Employed as operative & 8 & 1.65 & 1.62 \\
\hline
\end{tabular}

Sample size $=209 ; R^{2}$ in final regression $=0 \cdot 446$.

Table 5 Summary of additional models for outcome prediction

\begin{tabular}{|c|c|c|c|}
\hline Model & Covariate & Step & Sign \\
\hline $\begin{array}{l}\text { Model 1: } \\
\text { Dependent variable: disability index. } \\
\text { Excludes global health status, pain score } \\
\text { and disability index from } 1981 \text { as } \\
\text { possible covariates. } n=209 \text {, excludes } \\
\text { deceased subjects }\end{array}$ & $\begin{array}{l}\text { Work hours } \\
\text { Tender joints } \\
\text { Widow or widower } \\
\text { Visits to general practitioner } \\
\text { Venepunctures } \\
\text { Visits to surgeon }\end{array}$ & $\begin{array}{l}1 \\
2 \\
3 \\
4 \\
5 \\
6\end{array}$ & $\begin{array}{l}- \\
+ \\
+ \\
+ \\
+ \\
+\end{array}$ \\
\hline $\begin{array}{l}\text { Model 2: } \\
\text { Dependent variable: SUM of disability } \\
\text { index, global health status, pain. } \\
\text { Includes disability index, pain score } \\
\text { global health score from } 1981 \text { as } \\
\text { possible covariates. } n=209 \text {, excludes } \\
\text { deceased subjects }\end{array}$ & $\begin{array}{l}\text { Global } \\
\text { Disability } \\
\text { Education level } \\
\text { Employed as sales worker } \\
\text { Weekly work hours }\end{array}$ & $\begin{array}{l}1 \\
2 \\
3 \\
4 \\
5\end{array}$ & $\begin{array}{l}+ \\
+ \\
+ \\
+ \\
-\end{array}$ \\
\hline $\begin{array}{l}\text { Model 3: } \\
\text { Dependent variable: SUM of disability } \\
\text { index, global health status, pain score, } \\
\text { 1989. Excludes global health status, } \\
\text { disability, pain score, } 1981 \text { from } \\
\text { covariates. } \\
\text { n=209, excludes deceased subjects }\end{array}$ & $\begin{array}{l}\text { Weekly work hours } \\
\text { Tender joints } \\
\text { Venepunctures } \\
\text { Visits to general practitioner } \\
\text { Treatment with indomethacin } \\
\text { Visits to surgeon } \\
\text { Nursing home } \\
\text { White } \\
\text { Age }\end{array}$ & $\begin{array}{l}1 \\
2 \\
3 \\
4 \\
5 \\
6 \\
7 \\
8 \\
9\end{array}$ & $\begin{array}{l}- \\
+ \\
+ \\
+ \\
- \\
+ \\
+ \\
+ \\
+\end{array}$ \\
\hline $\begin{array}{l}\text { Model 4: } \\
\text { Dependent variable: disability index. } \\
\text { Includes disability index, global health } \\
\text { status, pain score as possible covariates. } \\
\mathrm{n}=263 \text {, includes deceased subject who } \\
\text { receive maximum for disability }=3\end{array}$ & $\begin{array}{l}\text { Disability index } \\
\text { Age } \\
\text { Work hours } \\
\text { Treatment with prednisone } \\
\text { Employed as farmers } \\
\text { Employed as operatives } \\
\text { Never married }\end{array}$ & $\begin{array}{l}1 \\
2 \\
3 \\
4 \\
5 \\
6 \\
7\end{array}$ & $\begin{array}{l}+ \\
+ \\
- \\
+ \\
+ \\
+ \\
+\end{array}$ \\
\hline $\begin{array}{l}\text { Model 5: } \\
\text { Dependent variable: disability index. } \\
\text { Excludes global health status, disability } \\
\text { index, and pain score as possible } \\
\text { covariates. } n=263 \text {, includes deceased } \\
\text { subjects who receive } 3 \text { for disability }\end{array}$ & $\begin{array}{l}\text { Age } \\
\text { Work hours } \\
\text { Treatment with prednisone } \\
\text { Tender joints } \\
\text { Treatment with ASA } \\
\text { Employed as operative }\end{array}$ & $\begin{array}{l}1 \\
2 \\
3 \\
4 \\
5 \\
6\end{array}$ & $\begin{array}{l}+ \\
- \\
+ \\
+ \\
+ \\
+\end{array}$ \\
\hline $\begin{array}{l}\text { Model 6: } \\
\text { Dependent variable: SUM of disability, } \\
\text { index pain score, global health status in } \\
1989 \text {. Excludes } 1981 \text { values of disability, } \\
\text { pain score, and global health status } \\
\text { as possible covariates. } n=263 \text {. Includes } \\
\text { deceased subjects who receive SUM }=9\end{array}$ & $\begin{array}{l}\text { Age } \\
\text { Treatment with prednisone } \\
\text { Work hours } \\
\text { Tender joints } \\
\text { Never married } \\
\text { Employed as operative }\end{array}$ & $\begin{array}{l}1 \\
2 \\
3 \\
4 \\
5 \\
6\end{array}$ & $\begin{array}{l}+ \\
+ \\
- \\
+ \\
+ \\
+\end{array}$ \\
\hline
\end{tabular}

that the initial value of the disability index was by far the best predictor, with a correlation coefficient of $0 \cdot 77$. The number of tender joints also generated a large correlation coefficient.

The sociodemographic variable which produced the highest correlation coefficient was average weekly hours of work in 1981. Employment as a professional was strongly and inversely related, whereas 'no occupation' was strongly and positively related to disability.

Use of specific drugs such as penicillamine, prednisone, steroids, aspirin, sodium aurothromalate, and fenoprofen was associated with higher disability in column 2 . Hydroxychloroquine and indomethacin showed a negative and statistically significant association, again in column 2.

Tables 3 and 4 give results from forward stepwise regressions treating the disability index in 1989 as the first dependent variable (table 3), the SUM of disability, pain, and global health status as the second dependent variable (table 4 ), and the 56 variables listed in table 2 as independent variables. No potential independent variables were excluded from the regression results reported in either tables 3 or 4 , as some variables which are not statistically significant in univariate analysis may become significant in multivariate analysis. ${ }^{14}$ Results from table 3 ignore patients who died. The regression in table 4 includes patients who died and records them as having the maximum SUM score of 9 . The first column of tables 3 and 4 lists in order the independent variables which appeared to be the most important predictors. The second column indicates the step at which each was entered. The third and fourth columns provide the estimated coefficients and their standard errors. The estimated coefficient is an estimate of the partial derivative. ${ }^{15}$ Sample sizes and final $R^{2}$ values appear at the bottom of each table.

The most powerful predictor of disability in 1989 (table 3) was disability in 1981 , with an $R^{2}$ value of 0.594 , followed by number of 1981 work hours, employment as farmer, and 1981 global health status. Table 4 , predicting the summary index of arthritis severitiy, again is led by disability, followed by age and use of prednisone.

Subjects who had never married have a summary score (SUM) roughly 1.05 higher than subjects in other marital status categories. The association between work hours and SUM can be assessed by considering the size of the estimated regression coefficient:-0.02. Working 20 or more hours a week is associated with a SUM that is roughly $0.4(-0.02 \times 20$ or more hours) lower than subjects who do not work 20 or more hours a week, other characteristics in the equation being equal. Subjects employed as operatives in 1981 report SUMs which are 1.65 higher than all others in occupational categories, including not working or retired.

The disability index measured in 1981 was chosen first by the stepwise regressions in tables 3 and 4. Global health status was the only other HAQ variable to enter as a statistically significant predictor in either table. Several sociodemographic variables appeared as significant 
Table 6 Predictors of change in disability: disability index 1989 minus disability index 1981 for living respondents

\begin{tabular}{llcl}
\hline $\begin{array}{l}\text { Independent variables } \\
\text { measured in 1981 }\end{array}$ & $\begin{array}{l}\text { Step } \\
\text { entered }\end{array}$ & $\begin{array}{l}\text { Coefficient } \\
\text { estimate }\end{array}$ & $\begin{array}{l}\text { Estimated } \\
\text { standard } \\
\text { error }\end{array}$ \\
\hline Disability index, 1981 & 1 & -0.159 & 0.059 \\
Work hours & 2 & -0.006 & 0.002 \\
Employed as farmer & 3 & 1.033 & 0.348 \\
Global health status & 4 & -0.003 & 0.002 \\
Employed as sales person & 5 & 0.314 & 0.148 \\
Widow or widower & 6 & 0.263 & 0.120 \\
Number of visits to a general practitioner & 7 & 0.057 & 0.025 \\
Treatment with indomethacin & 8 & -0.002 & 0.001 \\
Education level & 9 & 0.021 & 0.014 \\
\hline
\end{tabular}

Sample size $=209 ; R^{2}$ in final regression $=0.659$.

Table 7 Summary. List of best predictors, measured in 1981, for the disability index and the SUM of disability, pain, global health status, measured in 1989

\begin{tabular}{ll}
\hline Questionnaire indexes & Sociodemographic status \\
\hline Disability index (+) & Weekly work hours (-) \\
Pain scale (+) & Widow or widower (+) \\
Global health status (+) & Female sex (+) \\
Tender joints (+) & Age (t) \\
& Never married (+) \\
& Employed as operative (+) \\
\hline
\end{tabular}

,+- Indicates association with dependent variable.

predictors in the two tables, including work hours, employment as a farmer or an operative, female sex, never marrying, or being a widow or widower.

Table 5 presents abbreviated results from six additional forward stepwise regressions. Such analyses provide additional insights and serve as sensitivity analyses for the main results. These six regressions: ( $a$ ) sometimes included and sometimes excluded disability, pain, and health status as potential covariates; (b) sometimes included and sometimes excluded patients who died; and $(c)$ sometimes treated disability as the dependent variable and at other times treated SUM as the dependent variable. All eight combinations of $(a),(b)$, and $(c)$ were considered. Stepwise routines were again used to select the best predictors with variables required to have generated $p \leqslant 0 \cdot 15$.

Table 6 presents results from a forward stepwise regression in which the dependent variable was the change in the disability index from 1981 to 1989 . Notice that results in rows 2 to 9 are identical in tables 6 and 3 .

Table 7 summarises results of tables 3-6, listing those HAQ and socioeconomic variables most often appearing in the nine stepwise regressions.

\section{Discussion}

Disability in patients with rheumatoid arthritis after eight years may be predicted with greater confidence than previously reported ${ }^{1}$ if initial disability levels measured with the HAQ and socioeconomic variables are included as predictors. The prediction is robust, with $R^{2}$ values of 0.65 .

Several results invite further comment. (a) Positive correlations are exceptionally large between the disability index measured in 1981 and the same index measured in 1989. (b) The independent positive correlations are strong between pain scale, global health status, and number of tender joints measured in the initial years on the one hand, and the disability index measured in later years on the other. (c) The positive correlation between education level and the disability index was unexpected. (d) Higher age and female sex are strong positive predictors of worsening disability over time. (e) Number of work hours appears to be the most important sociodemographic predictor. (f) Subjects who had never married, widows, and widowers deteriorate more rapidly than married subjects (g) Employment as a farmer or operative also appears to predict rapid deterioration. (h) Results in tables 3 and 6 are almost identical.

The strongest correlations by far are those between old and new values for the disability index and old values of the disability index and new values of the SUM of the disability, pain, and global health status. This is not surprising given that these correlations are between old and new values of the same variable, but this does not negate the major predictive power of this variable. The initial values of many characteristics, including weight and blood pressure, are often the best predictors of subsequent values for those same characteristics. If a doctor is looking for a predictor of the future course of the disease, the patient's score on the HAQ disability index is the best single predictor. Regression to the mean probably reduces the size of the estimated coefficient to less than $1 \cdot 0$; some subjects with exceptionally high or low disability scores in 1981 are there because of bad or good health on the particular day they answered the questionnaire. This measurement artefact will decrease, on average, with time. ${ }^{14}$

The results for pain scale and global health status underscore a strong colinearity with disability. When the disability index was excluded from the stepwise regression, pain scale became the new best predictor and was the first variable selected by the stepwise routine. When the disability index and the pain scale were omitted, global health status rose to the top of the stepwise list. These results point to a common problem with stepwise routines. If two variables (for example, disability index and pain scale, or age and duration) are highly correlated with each other, then when one of these variables is chosen at an early step in a stepwise regression, the other will decrease in predictive power and may not be included in the model. Hence, one model may include disability index but not pain scale, and another may include pain scale but not the disability index. Results of a stepwise regression procedure are thus potentially arbitrary. ${ }^{15}$ Moreover, a different sample may identify different predictive factors. Pain scale, global health status, and the disability index may thus be capturing much of the same information. Nevertheless, in our sample the disability index was the best predictor of the three.

Education level has been found to be strongly negatively correlated with the development of disability in patients with rheumatoid arthritis, ${ }^{16}{ }^{17}$ yet these results suggest the opposite. There are reasons, however, not to emphasise the education results of this study. 
First, the statistically significant univariate correlation was negative, as expected, ${ }^{16}{ }^{17}$ in table 2. Second, education level was selected in only one of the many regressions performed. The anomaly, most probably, is the result of the strong correlation between work hours and years of education. A positive correlation coefficient of $0 \cdot 28$, statistically significant at the 0.006 level, was calculated using the 1981 data. There is evidence that years of education is one of the strongest predictors of the number of hours worked in society at large. ${ }^{18} \mathrm{We}$ are unaware of any previous studies of education and rheumatoid arthritis which accounted for work hours. Our results suggest that this omission may be an oversight, as work hours are colinear with education level and are strongly correlated with the disability index. It is also possible that the relatively narrow range of education level in this sample reduced the effects of this variable.

The results for male sex and age were surprising. It is known that men have less disability than women from rheumatoid arthritis. These results suggest that men, even with the same level of disability as women in 1981, do not have the same high rate of deterioration in their health as women with time.

Age is partly dependent on its relationship with other temporal variables. For instance, as age increases, disease duration also increases. Also, comorbid conditions generally increase with age. Importantly, increasing age also means increasing frailty, so that the same severity of disease might lead to a greater functional loss. In this sense, age itself represents comorbidity. Thus older subjects develop a given degree of disability more rapidly than younger subjects even when they begin with the same initial level of disability.

The respondent's answers to the weekly work hours question provided important insights. Weekly work hours was consistently the strongest sociodemographic predictor of the course of disability. It appeared to be a stronger predictor than either gender, age, race, or education, all of which have received considerable attention in the past.

We regard the results for the work hours variable as important, and the results have implications for the interpretation of earlier research. As already mentioned, part of the strong education and arthritis correlations found elsewhere might be due in part to the strong association that education has with work hours as shown in many social science studies. ${ }^{19}$ The correlations have one obvious, and another intriguing, explanation. The obvious explanation involves the 'healthy worker' effect whereby the fact that a subject is employed indicates that he or she is not substantially disabled. Severe rheumatoid arthritis certainly can result in job loss. ${ }^{20}$ The second explanation, however, suggests that employment itself may confer some health benefits. Verbrugge ${ }^{21}$ attributes much of the higher age adjusted morbidity rates of women compared with men to their 'inactivity'that is, in part their lack of work for pay outside the home. There is also emerging evidence that sustained unemployment is associated with loss of self efficacy, ${ }^{22}$ depression, ${ }^{23-25}$ and high blood pressure. ${ }^{26}$ One study found current unemployment to be among a few powerful correlations of future probabilities of receiving workers' compensation or social security disability benefits. ${ }^{27}$ Employment provides exercise, earnings, and increases in self efficacy. Studies on women suggest that work has a strong and positive effect on women's health over and above the 'healthy worker' effect. ${ }^{28} 29$

If this second explanation has merit, then interesting policy implications can be drawn. Attempts to encourage employment, especially for women over 50, through affirmative action or training programmes, might result in improvements in health status in rheumatoid arthritis. Lower unemployment rates might similarly decrease the rate of deterioration.

The results for being a widow or widower and never married were not unexpected. Bereavement following loss of a spouse has often been linked to health problems. ${ }^{30} \mathrm{~A}$ life without a loving partner is also associated with health problems. $^{31}$

We are unaware of previous studies which attempt to link specific occupations with rapid or slow progression of rheumatoid arthritis. Our results suggest that being employed as a farmer or operative is deleterious, although sample sizes for these occupations were small. Examples of operative jobs are assemblers, blasters, gas station attendants, meat cutters, mine workers, and drill press operatives. It might be that strenous work, sometimes outdoors in unpleasant weather, which is necessary for many operative jobs, leads to more rapid deterioration. ${ }^{32}{ }^{33}$ It could also be that the low income and lack of personal freedom associated with operative jobs weaken the immune system in the same way that these factors have been shown to increase blood pressure. ${ }^{25}$ Whatever the reasons, our results warrant further study into possible links between occupation and rheumatoid arthritis. The results for being a farmer as a predictor of worsening disability should be neglected. Only two subjects reported employment as farmers in 1981. Subsequent analyses showed that both subjects changed their stated occupation in later years.

One problem with the results and discussion of tables 2 to 5 is that our sample had rheumatoid arthritis for an average of 12 years at baseline. It might be argued that by this stage there was little possibility for further disease progression. The mean increase for the continuous living and participating cohort was $\mathbf{0 . 0 7}$ over eight years. In this view, the strength of 1981 disability index as a covariate in predicting the 1989 index is not surprising.

There are two responses to this criticism. First, the mean increase of 0.07 only reflects the average. The standard deviation of the change in the disability index between 1989 and 1981 was 0.536 and the change in the index ranged from -1.25 to 2.5 among the 209 continuously enrolled subjects. There was apparently considerable variation between the 1989 and 1981 disability index for some people. Second, we ran a stepwise regression explaining the 1981 to 1989 changes in the disability index. Results are 
given in table 6. The 1981 disability index again entered the regression first. The additional covariates chosen by the stepwise routine also appear in the earlier analyses in tables 3 to 5 . These covariates include work hours, farmers, widows, number of general practitioner visits, sales workers, global health score, treatment with indomethacin, and education.

The disability index coefficient is negative in table 6, predicting the 1981 to 1989 change in the disability index but was positive in tables 3 to 5 , predicting 1989 values. The negative sign in table 6 could result from one or two factors. First, there could be a limiting factor due to the maximum score of 3 . Subjects with scores of 2.5 in 1981 can only increase to a maximum of 3.0 by 1989 . Subjects with initial scores of $1 \cdot 0$, however, could increase to $2 \cdot 0$ or more eight years later. In spite of this, 2.5 is a rare score. Few people ever reach $2 \cdot 5$, and even fewer reach $3 \cdot 0$. A second explanation may be more convincing. The negative signs could result from a rapid increase of disease severity in low and middle values but slow worsening in high values. Plateaux may be more common at high than low or middle values of the disability index.

The covariates in table 6 are strikingly similar to those in table 3. This is not surprising given the mathematical similarity of the two regressions. Consider equation (1):

$$
\text { DI89-DI81 }=\beta_{1}+\beta_{2} D I 81+X \beta_{3}
$$

where DI89 and DI81 indicate the disability indexes in 1989 and $1981 ; X$ is a vector of covariates; $\beta_{1}$ is an intercept; $\beta_{2}$ is a slope parameter for DI81; and $\beta_{3}$ is a vector of slope parameters for $\boldsymbol{X}$. Notice that equation (1) can be rewritten as:

$$
\text { DI89 }=\beta_{1}+\beta_{2} \mathrm{DI} 81+X \beta_{3}+\beta_{4} \mathrm{DI} 81
$$

where $\beta_{4}=1$. Collecting similar DI81 terms yields:

$$
\text { DI89 }=\beta_{1}+\left(\beta_{2}+\beta_{4}\right) D I 81+X \beta_{3}
$$

or

$$
\text { DI89 }=\beta_{1}+\alpha \mathrm{DI} 81+X \beta_{3}
$$

where $\alpha=\beta_{2}+\beta_{4}$.

Equation (1) is similar to the regression in table 6. Equation (4) is similar to the regression in table 3. Notice that equations (1) to (4) imply $\alpha=\beta_{2}+\beta_{4}$. The estimate of $\alpha$ from table 3 is $0 \cdot 84$. The estimate of $\beta_{2}$ from table 6 is $-0 \cdot 16$. Consequently, $0 \cdot 84=-0 \cdot 16+\beta_{4}$ or $\beta_{4}=1 \cdot 0$, which is required by equation 2 . For rows 2 to 9 , the results in table 3 are identical with those in table 6.

We conclude that no new information about covariates other than DI81 result from an extensive analysis of the change in severity measures versus an analysis of only 1989 measures provided 1981 measures of severity are always included as covariates.

A number of variables measured in 1981 greatly aided in the prediction of the disability status of patients in 1989. The prediction is robust, and may explain as much as $66 \%$ of the variance. The initial value of the disability index is the dominant predictive factor, aided by female sex, pain scale, age, global health status, number of tender joints, decreased work hours, and non-married status. We believe that blue collar occupations and number of work hours deserve greater attention in future research. Finally, future researchers should attempt to enrol people in the study who were only recently diagnosed as having rheumatoid arthritis.

The authors thank Mary Peterson for secretarial assistance. This research was supported in part by grants from the National Institutes of Health (AM21393) to ARAMIS (American Rheumatism Association Medical Information System), and the Stanford Arthritis Center (AM20610).

1 Sherrer Y S, Bloch D A, Mitchell D M, Young D Y, Fries $J$ F. The development of disability in rheumatoid arthritis. Arthritis Rheum 1986; 29: 494-500.

2 Jacoby R K, Jayson M I V, Kosh J A. Onset, early stages and prognosis in rheumatoid arthritis: a clinical study of 100 patients with 11 year follow up. BMF 1973; 2: 96-100.

3 Hart F D. Presentation of rheumatoid arthritis and its relation to prognosis. BMF 1977; 2: 621-4.

4 Wawrzynska-Pagowska J, Brzezinska B, Brzozoska M, et al. Observations on the symptoms and signs of 'early' rheumatoid arthritis in a prospective study. Acta Rheumatol Scand 1970; 16: 99-105.

5 Kellgren J H, O'Brien W $M$. On the natural history of heumatoid arthritis in relation to the sheep cell agglutination test [abstract]. Arthritis Rheum 1962; 5: 115.

6 Gordon D A, Stein J L, Broder I. The extra-articular features of rheumatoid arthritis: a systematic analysis of 127 cases. Am 7 Med 1973; 54: 445-52

7 Duthie J J R, Brown P E, Truelove L H, Baragar F D, Lawrie A J. Course and prognosis in rheumatoid arthritis. Ann Rheum Dis 1964; 23: 193-202.

8 Liang $M \mathrm{H}$, Jette A M. Measuring functional ability in chronic arthritis: a critical review. Arthritis Rheum 1981; 24: $80-6$.

9 Feigenbaum S L, Masi A T, Kaplan S B. Prognosis in heumatoid arthritis: a longitudinal study of newly diagnosed younger adult patients. Am F Med 1979; 66: 377-84.

10 Slottje D J. The structure of earmings and the measurement of income inequality in the U.S. New York: North-Holland, 1989: 22.

11 US Department of Commerce. 1980 census of the population, general social and economic characteristics: California. Weraington, DC: Government Printing Office, 1983.

12 Fries J F, Spitz P W, Young D Y. The dimensions of health outcomes: the health assessment questionnaire, disability and pain scales. I Rheumatol 1982; 9: 789-93.

13 Fries J F, Spitz P W, Kraines R G, et al. Measurement of patient outcome in arthritis. Arthritis Rheum 1980; 23: 137-45.

14 Maddala G S. Introduction to econometrics. New York: MacMillan, 1988.

15 Leigh J P. Assessing the importance of an independent variable in multiple regression: is stepwise unwise? $\mathrm{f}$ Clin Epidemiol 1988; 41: 669-77.

16 Pincus T, Callahan L F. Formal education as a marker for increased mortality and morbidity in rheumatoid arthritis. 7 Chronic Dis 1985; 38: 973-84.

17 Callahan L F, Pincus T Association between clinical status questionnaire scores and formal education level in persons with systemic lupus erythematosus. Arthritis Rheum 1990 33: 407-11.

18 Ehrenberg R G, Smith R S. Modern labor economics: theory and public policy. Glenview, IL: Scott, Foresman, 1988.

19 Killingsworth M. Labor supply. Cambridge: Cambridge University Press, 1983.

20 Yelin E, Meenan R, Nevitt M, Epstein W. Work disability in rheumatoid arthritis. Ann Intern Med 1980; 93: 551-6.

21 Verbrugge L M. The twain meet: empirical explanations of sex differences in health and mortality. I Health Soc Behav 1989; 30: 282-303.

22 Arnetz B, Brenner S O, Levi L, et al. Immune function in unemployed women. Psychosom Med 1987; 49: 3-12.

23 Ensminger M E, Celentano D D. Gender differences in the effect of unemployment on psychological distress. Soc Sci Med 1990; 30: 469-77.

24 Hall E M, Johnson J V. Depression in unemployed Swedish women. Soc Sci Med 1988; 27: 1349-55.

25 Karasek R, Theorell T. Healthy work: stress, productivity, and the reconstruction of working life. New York: Basic Books, 1990: 305-7.

26 Cobb S, Kasl S. The consequences of job loss. Cincinnati: National Institute for Occupational Safety and Health; 1977 NIOSH Publication No.: 77-224.

27 Leigh J P. The effects of unemployment on the probability of suffering

28 Verbrugge $L$ M. Gender and health: an update on hypotheses and evidence. F Health Soc Behav 1985; 26: 156-82.

29 Jennings S, Mazaik C, McKinlay S. Women and work: an investigation of the association between health and employ 
ment status in middle-aged women. Soc Sci Med 1989; 19: 423-31.

30 Parker C M, Benjamin B, Fitzgerald R G. Broken heart: A statistical study of increased mortality among widowers. $B M \mathcal{F} 1969 ;$ i: $740-3$

31 Berger M C, Fleisher B M. Husband's health and wife's labor supply. Fournal of Health Economics 1984; 3: 63-75.
32 Anderson J J, Felson D T. Factors associated with osteoarthritis of the knee in the first NHANES: evidence for an association with overweight, race, and physical demands of work. Am f Epidemiol 1988; 128: 179-89.

33 Milham S Jr. Using multiple cause of death coding in occupational mortality studies. Am $\mathcal{F}$ Ind Med 1988; 14: occupa. 